\title{
INVOLUÇÃO UTERINA PÓS-PARTO EM BOVINOS
}

\author{
Aline Sousa Camargos ${ }^{1 *}$, Eunice Oba ${ }^{2}$ \\ ${ }^{1}$ Instituto Federal Goiano Campus Morrinhos, Departamento de Zootecnia, Morrinhos, GO. ${ }^{2}$ Universidade Estadual \\ Paulista - UNESP, Departamento de Reprodução Animal e Radiologia Veterinária, Botucatu, SP. E-mail: \\ aline.camargos@ifgoiano.edu.br
}

\begin{abstract}
RESUMO
A involução uterina é o principal processo fisiológico durante o período puerperal. Este processo é marcado por modificações que ocorrem no útero da fêmea, após o parto, levando o órgão à recuperação das transformações ocorridas durante o período da prenhez, para finalmente atingir volume, tamanho, posição e recuperação da capacidade reprodutiva para uma futura gestação. A involução uterina inclui uma complexa série de eventos que incluem contrações do miometriais, reparação do endométrio e redução do fluxo sanguíneo. Fatores como distocia, retenção de placenta e número de partos podem influenciar a duração do processo de involução.
\end{abstract}

Palavras-chave: miométrio; prostaglandina F2alfa; puerpério; reparação endometrial; vacas

\section{POSTPARTUM UTERINE INVOLUTION IN CATTLE}

\begin{abstract}
The uterine involution is the main physiological process during the puerperal period. This process is marked by changes that occur in the female's uterus after parturition, leading the uterus to recover the changes that occurred during the period of pregnancy, to finally achieve volume, size, position and recovery of the reproductive capacity for a future pregnancy. The uterine involution includes a complex series of events that include myometrial contractions, endometrial repair and reduced blood flow. Factors such as dystocia, retained placenta and number of deliveries can influence the duration of the involution process.
\end{abstract}

Keywords: cows; endometrial repair; F2alpha prostaglandin; myometrium; postpartum

\section{INTRODUÇÃO}

O objetivo primário do produtor de leite e carne é maximizar os lucros, ou seja, tornar a atividade economicamente eficiente e lucrativa. No entanto, a bovinocultura no Brasil tem enfrentado dificuldades para se manter viável. Uma das principais causas deste problema deve-se, principalmente, à baixa eficiência reprodutiva dos rebanhos. Isto porque sem gestação e parto não há lactação nem bezerros, o que levará à consequente queda na produção de leite e carne (MACHADO et al., 2003).

O intervalo entre partos médio do rebanho nacional é superior aos 18 meses. Para a avaliação da eficiência em rebanhos bovinos, este intervalo é uma variável de grande importância. Porém, trata-se de um índice global que reflete a condição geral da situação reprodutiva da propriedade. Este índice depende principalmente de duas variáveis, que seriam a duração do período do parto ao reinício da atividade reprodutiva (intervalo parto - 10 estro), e também do tempo gasto para que se estabeleça uma nova gestação (número de serviços/concepção; FERNANDES et al., 2002). 
Como a duração da gestação não pode ser alterada, para se melhorar os índices reprodutivos de um plantel, é necessário que as vacas retornem à atividade reprodutiva rapidamente após o parto e que tenham condições ótimas de concepção, ou seja, boa fertilidade (FERNANDES et al., 2004).

Para o retorno à atividade reprodutiva, é importante uma involução uterina rápida (ZANCHET, 2005). Foi demonstrado que a liberação de prostaglandina F2 $\alpha$ ( PGF $_{2 \alpha}$ ) após o parto intensifica o processo de involução (KINDHAL et al., 1999). No entanto, o mecanismo de ação deste hormônio no útero bovino ainda não está de todo elucidado.

Para maximizar os índices de eficiência reprodutiva de um rebanho, seja por meio de intervenções no manejo reprodutivo, nutricional e sanitário ou pela utilização de protocolos hormonais, deve-se primeiro conhecer a fundo os aspectos fisiológicos que envolvem o período pós-parto de vacas. Deste modo, este trabalho tem por objetivo revisar a fisiologia do mecanismo de involução uterina na espécie bovina.

\section{REVISÃO DA LITERATURA}

\section{1 ÚTERO BOVINO}

O útero da vaca é bipartido, apresentando cérvix, corpo do útero e 2 cornos uterinos (direito e esquerdo). O órgão não-gestante apresenta comprimento médio de $10 \mathrm{~cm}, 3 \mathrm{a} 4 \mathrm{~cm}$ e 35 a $40 \mathrm{~cm}$ para cérvix, corpo e cornos uterinos, respectivamente. Está localizado quase em sua totalidade na cavidade abdominal em bovinos adultos (SISSON, 1986).

O útero é constituído por três camadas teciduais: perimétrio (serosa), miométrio (muscular) e endométrio (mucosa) (HAFEZ; JAINUDEEN, 1995).

O perimétrio é a camada mais externa, formada predominantemente por tecido conjuntivo frouxo. O miométrio consiste em uma espessa camada de células musculares lisas. $O$ endométrio é constituído por tecido epitelial e conjuntivo, onde podem ser observadas as glândulas endometriais. Nesta camada uterina, existem regiões específicas denominadas carúnculas, proeminências ovais ( $15 \mathrm{~mm}$ de comprimento) formadas por espessamentos circunscritos da lâmina própria, ricos em fibroblastos e suprimento sanguíneo (SISSON, 1986).

Durante a gestação, o útero aumenta consideravelmente em tamanho e espessura. Há tanto hipertrofia como hiperplasia das células musculares lisas miometriais e aumento do calibre dos vasos sanguíneos uterinos. No endométrio, se desenvolvem as carúnculas maternas até cerca de 10 a $12 \mathrm{~cm}$ de comprimento, onde se ligam os cotilédones placentários (SENGER, 2003; SISSON, 1986).

\section{INVOLUÇÃO UTERINA}

Imediatamente após o parto, inicia-se o processo de involução uterina. Este mecanismo inclui um conjunto de modificações que ocorrem no útero da fêmea, levando o orgão à recuperação das transformações ocorridas durante o período da prenhez, para finalmente atingir volume, tamanho, posição e recuperação da capacidade reprodutiva para uma futura gestação (KOZICKI, 1998).

A espécie bovina apresenta involução uterina lenta, com duração que varia de 30 a 120 dias (LANDIM-ALVARENGA, 2006). A massa do tecido uterino deve reduzir mais de 10 vezes dentro de 4 semanas. O útero, logo após o parto normal, pesa aproximadamente $10 \mathrm{~kg}$, reduzindo para 0,7-0,8 kg até a 6a semana após o parto (FERNANDES; FIGUEIREDO, 2007).

Nos primeiros quatro dias após o parto, a involução uterina é rápida, seguindo uma escala logarítmica, tornando-se mais lenta do 4ㅇ ao 9ㅇ dia. Nesta fase, chamada período refratário do útero, e que vai do 4ㅇ ao 7-8으 dia pós-parto, o útero permanece praticamente inerte, não respondendo aos estímulos de hormônios que teriam a capacidade de provocar a contratilidade. $A$ partir do 10 dia, e estendendo-se até cerca do 14을 dia pós-parto, novamente o processo de 
involução uterina é retomado, quando já existirão alguns folículos ovarianos atuantes, com produção de quantidades significativas de $17 \beta$-estradiol. Esse hormônio irá favorecer a involução uterina, completando-se entre a 4ạ e a 7ạ semana pós-parto, embora as mudanças após 20-25 dias pós-parto sejam pouco perceptíveis (KOZICKI, 1998).

A partir da década de 70, os critérios utilizados para avaliar a involução uterina passaram a ser, basicamente, verificar o tempo de retorno do útero à posição normal na cavidade pélvica, pela palpação retal (SÁNCHEZ et al., 1999). Outros aspectos a serem avaliados são a recuperação do tamanho da cérvix (KASIMANICKAM et al., 2004), do tamanho e da simetria dos cornos uterinos e do restabelecimento da consistência e do tônus uterino (LOPES, 2007; MELENDEZ et al., 2004).

Ao exame ultrassonográfico, é possível mensurar com maior precisão o diâmetro dos cornos uterinos e cérvix, além de permitir a visualização do conteúdo uterino (SHELDON et al., 2006; KASIMANICKAM et al., 2004; MELENDEZ et al., 2004). Segundo Melendez et al. (2004), podese ainda estimar a espessura do miométrio, subtraindo-se o diâmetro do lúmen uterino do diâmetro total do útero.

O mecanismo de involução uterina envolve uma complexa série de eventos que incluem contrações miometriais, reparação do endométrio (SCHIRAR; MARTINET, 1982) e redução do fluxo sanguíneo uterino (KRUEGER et al., 2009).

\subsection{CONTRAÇÃO MIOMETRIAL}

Durante o processo de involução, o miométrio apresenta contrações musculares, que auxiliam a sua redução volumétrica (HERTELENDY; ZAKAR, 2004). Em raças leiteiras, as células miometriais possuem $700 \mu \mathrm{m}$ no dia do parto, reduzindo para $200 \mu \mathrm{m}$ poucos dias depois (SENGER, 2003). O tecido miometrial tem a capacidade de adaptar-se rapidamente à diminuição de conteúdo, sem prejuízo para o tônus muscular. A contração das células musculares (miometriais) é cálcio-dependente. A liberação de cálcio no citoplasma dessas células é estimulada por ação hormonal (HERTELENDY; ZAKAR, 2004).

$\mathrm{O}$ intervalo entre as contrações miometriais aumenta à medida que avança o puerpério. $\mathrm{Na}$ maioria das espécies domésticas, as contrações miometriais ocorrem em intervalos de 3-4 minutos na primeira semana pós-parto (SENGER, 2003).

\subsection{REPARAÇÃO DO ENDOMÉTRIO}

A placentação da vaca é do tipo adeciduado (JAINUDEEN; HAFEZ, 1995). A placenta só é expulsa algumas horas após o nascimento. Após o parto, as carúnculas e o restante da parede uterina iniciam um processo semelhante a um processo inflamatório (BENCHARIF et al., 2000).

Para que haja o restabelecimento do endométrio, é necessário acontecer o descolamento fisiológico da placenta. Inicia-se então outro processo onde as criptas endometriais, que eram profundas, tornam-se mais aplainadas, as vilosidades coriônicas diminuem de tamanho devido à redução do fluxo sanguíneo pelo corte do cordão umbilical, bem como ocorrerá a colagenização dos espaços nos placentomas (GRUNERT; BIRGEL, 1982).

Sabe-se que, durante os primeiros 7 a 10 dias pós-parto, há descarga de líquido chamado lóquio. Esse lóquio é formado por substâncias remanescentes do fluido fetal, sangue dos vasos rompidos e grânulos de enzimas proteolíticas formados no endométrio durante a gestação (GRUNERT; BIRGEL, 1982). Células binucleadas e fagocitárias iniciam mudanças necróticas pelas camadas celulares da superfície endometrial (carúnculas) destruídas pela degeneração gordurosa, já nas primeiras 48 horas pós-parto, dando origem à secreção serosa na cavidade uterina. No quinto dia pós-parto, as carúnculas apresentam superfície necrótica de 1 a $2 \mathrm{~mm}$ de espessura. Posteriormente, este tecido necrótico será eliminado no lóquio (NOAKES, 1991). Inicialmente, o volume de lóquio é de aproximadamente $1500 \mathrm{ml}$, reduzindo para cerca de $500 \mathrm{ml}$ no 8ㅇa dia (GRUNERT; BIRGEL, 1982). 
Clinicamente, quanto mais viscosa e inodora for a descarga loquial, melhor é o prognóstico reprodutivo. A regeneração do endométrio ocorre imediatamente após o parto naquelas áreas menos danificadas e completa-se na região intercaruncular em torno do 8o dia pós-parto. A completa reepitelização das carúnculas, que inicia-se na terceira semana pós-parto, originada em grande parte pelo crescimento celular centrípeto das células que circundam as glândulas uterinas, completa-se entre o 25 e o 60 dias pós-parto (NOAKES, 1991; ARTHUR et al., 1989).

\subsection{AÇÃO HORMONAL}

Devido ao prolongado período de inibição durante a gestação, pelo contínuo feed-back negativo da progesterona secretada pelo corpo lúteo e placenta, a hipófise torna-se temporariamente refratária no pós-parto (LAMMING et al., 1979). O período do parto ao reinício da atividade ovariana caracteriza-se, do ponto de vista hormonal, pela ausência de esteróides sexuais na circulação e por níveis elevados de prostaglandina $F 2$ alfa $\left(\mathrm{PGF}_{2 \alpha}\right)$, de origem predominantemente uterina (TORIBIO et al., 1994).

\subsubsection{PROSTAGLANDINA $F_{2 \alpha}$ E RECEPTOR FP}

A $P F_{2 \alpha}$ é um metabólito do ácido aracdônico, que é liberado dos fosfolipídeos pela fosfoslipase $A_{2}$ (PLA2). O endométrio bovino contém grandes quantidades de ácido aracdônico e tem a habilidade de metabolizá-lo em uma variedade de produtos (AULETTA; FLINT, 1988). A síntese de prostaglandinas ocorre em etapas pela enzima peroxidase citosólica e por dois tipos de enzimas ligadas à membrana (cicloxigenase-COX e isomerase endoperoxidase) (SALAMONSEN; FINDLAY, 1990).

A primeira etapa da produção de prostaglandina é catalisada pela enzima COX (prostaglandina $\mathrm{G} / \mathrm{H}$ sintase) que converte ácido aracdônico em uma forma instável de $\mathrm{PGG}_{2}$. $A$ peroxidase converte rapidamente $\mathrm{PGG}_{2}$ em $\mathrm{PGH}_{2}$. $\mathrm{PGG}_{2}$ e $\mathrm{PGH}_{2}$ são moléculas biologicamente ativas instáveis, chamadas endoperóxidos. $\mathrm{A} \mathrm{PGH}_{2}$ é convertida em $\mathrm{PGF}_{2 \alpha}$ e outras prostaglandinas pela endoperóxido isomerase (prostaglandina sintase) e outras peroxidases (SALAMONSEN; FINDLAY, 1990; OKUDA et al., 2002).

A expressão do gene COX nas células do endométrio bovino é influenciada por esteróides ovarianos. Progesterona e estrógeno podem afetar diretamente a secreção de PGF $_{2 \alpha}$ basal pelo endométrio, regulando a resposta endometrial à ocitocina e outros fatores de regulação (XIAO et al., 1998). A progesterona estimula a produção basal de $\mathrm{PGF}_{2 \alpha}$ pelas células e tecidos do endométrio bovino, mas inibe a secreção de ocitocina estimulada por PGF ${ }_{2 \alpha}$ (SKARZYNSKI et al., 1999). O estradiol diminui a produção basal de $\mathrm{PGF}_{2 \alpha}$ pela down-regulation da COX-mRNA (XIAO et al., 1998), e aumenta a produção de $\mathrm{PGF}_{2 \alpha}$ estimulada pela ocitocina em células endometriais de bovinos cultivadas por longo período (OKUDA et al., 2002).

No endométrio bovino, há a expressão de duas enzimas que conduzem diretamente a produção de $\mathrm{PGF}_{2 \alpha}$, a PGF sintase (PGFS) e PGE2-9-ketoredutase (9K-PGR). A PGFS catalisa a redução de $\mathrm{PGH}_{2}$ em $\mathrm{PGF}_{2 \alpha}$, enquanto a $9 K-P G R$ é uma enzima dependente de $\mathrm{NADPH}$, que catalisa a conversão de $\mathrm{PGE}_{2}$ em $\mathrm{PGF}_{2 \alpha}$. A PGF $\mathrm{PG}_{2 \alpha}$ e outras prostaglandinas não são armazenadas nas células, sendo liberadas imediatamente após a síntese (ASSELIN; FORTIER, 2000).

A PGF $_{2 \alpha}$ é primariamente secretada pela região intercaruncular da superfície epitelial uterina, sendo considerada a maior contribuinte para a regulação dos processos reprodutivos (ASSELIN et al., 1998; SKARZYNSKI et al., 2000). A habilidade do endométrio bovino de produzir prostaglandina varia durante o ciclo estral e puerpério (OKUDA et al., 2002). Durante o ciclo estral, o útero libera $\mathrm{PGF}_{2 \alpha}$ em séries de pulsos de curta duração por 2-3 dias durante e após a luteólise (KINDHAL et al., 1981).

No processo fisiológico de separação e expulsão da placenta nos bovinos (HORTA, 1995), a $\mathrm{PGF}_{2 \alpha}$ é liberada antes do início do parto e acarreta a luteólise pré-parto. Após o parto, na fase do 
puerpério precoce, o fenômeno endócrino dominante é a liberação de grande quantidade de prostaglandina, devido principalmente à elevada incidência de contaminação bacteriana. Os níveis

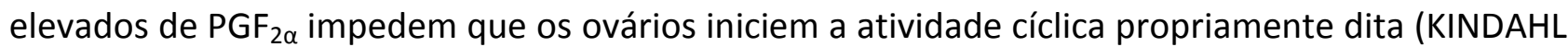
et al., 1992; JAINUDEEN; HAFEZ,1995), além de intensificar o processo de involução uterina (FERNANDES et al., 2003; KINDHAL et al., 1999).

Vários pesquisadores têm procurado esclarecer o mecanismo de ação da prostaglandina no pós-parto, porém o mesmo ainda não está de todo elucidado (MACHADO et al., 2003).

Durante o período puerperal, há presença de metabólitos da prostaglandina (PGFM) no sangue, e estes estão correlacionados à involução uterina (BEKANA et al., 1999). O nível de PGFM alcança seu valor máximo 2-3 dias após o parto e diminui progressivamente até retornar a seu nível basal aos 15 dias pós-parto (GUILBAULT et al., 1984). O período onde a produção de prostaglandina pelo útero é maior coincide com a involução uterina, comprovando ser esta a principal substância relacionada a este processo (TORIBIO et al., 1994).

A PGF $_{2 \alpha}$ estimula a atividade da camada muscular uterina (miométrio) após o parto (FERNANDES et al., 2003). Se a duração da liberação de PGF $_{2 \alpha}$ for muito curta, a involução uterina estará prejudicada; já se for mais longa, o processo involutivo do útero será mais acelerado (KINDHAL et al., 1992).

Nos animais que não apresentam retenção de placenta após o parto, há inicialmente nos placentomas $\mathrm{PGF}_{2 \alpha}$ em concentrações mais elevadas do que nas vacas que tiveram a placenta retida (GRUNERT; BIRGEL,1982).

As prostaglandinas mediam suas ações por meio de receptores transmembrana acoplados à proteína G (GPCRs) específica para cada prostanóide (ANDERSON et al., 1999). O receptor da $\mathrm{PGF}_{2 \alpha}$ é conhecido como receptor FP (MILNE; JABBOUR, 2003). Na espécie bovina, os estudos do receptor FP têm sido limitados ao corpo lúteo.

No entanto, estudos em mulheres identificaram o miométrio como o principal alvo da $\mathrm{PGF}_{2 \alpha}$. O receptor FP é expresso em grande quantidade no miométrio humano (MATSUMOTO et al., 1997), com concentrações nanomolares de $\mathrm{PGF}_{2 \alpha}$ induzindo contrações em tiras de miométrio in vitro (SENIOR et al., 1992). A evidência de que o miométrio é o maior alvo para PGF ${ }_{2 \alpha}$ é reforçada pelas observações de receptor FP de rato, onde a perda de contratilidade miometrial e falha na indução do parto são as maiores mudanças fenotípicas (SUGIMOTO et al., 1997; MILNE; JABBOUR, 2003).

No endométrio, a expressão do receptor FP está localizada predominantemente nas células epiteliais com regulação temporal, onde o nível de expressão mais alto é detectado no endométrio em proliferação. Após o tratamento com PGF exógena, foi observada ativação do mecanismo PLC e liberação de inositol fosfato. Os fatores que regulam a expressão do receptor FP durante a fase proliferativa no endométrio humano não estão claros. No entanto, tem sido mostrado que os hormônios esteróides afetam a expressão deste receptor (MILNE; JABBOUR, 2003).

Além de estar presente nas células epiteliais, o receptor FP também está localizado nas células perivasculares do endométrio humano ao longo do ciclo menstrual. Esta expressão é mais comum na camada de músculo liso da região perivascular, onde o FP possivelmente media efeitos vasopressores que estão associados à função da PGF ${ }_{2 \alpha}$ na vasculatura (GRIFFIN et al., 1998).

Não há possibilidade de ocorrer ovulação pós-parto, até que a liberação de PGF $_{2 \alpha}$ cesse ou que esteja muito próxima aos níveis basais, fato que ocorre a partir da quarta semana após o parto em bovinos (KINDAHL et al.,1992).

Assim como a $\mathrm{PGF}_{2 \alpha}$ endógena, seus análogos sintéticos (cloprostenol sódico, dinoprost, fluprostalene, fluprostenol, luprostil e prostaleno) atuam de forma semelhante sobre a involução uterina. Os protocolos de cloprostenol sódico no pós-parto têm sido os mais utilizados, apresentando efeitos benéficos sobre a eficiência reprodutiva dos bovinos (FERRAZ, 2006). 


\subsection{REDUÇÃO DO FLUXO SANGUÍNEO}

Em vacas holandesas no puerpério, a perfusão uterina diminui drasticamente na primeira semana pós-parto (FORD et al., 1982; GUILBAULT et al., 1984), acompanhando a involução uterina que diminui de $8 \mathrm{~kg}$ no dia do parto até $3,6 \mathrm{~kg}$ após oito dias (GIER; MARION, 1968). Entre os dias sete e 28 pós-parto, o volume de fluxo sanguíneo (BFV) uterino continua diminuindo discretamente (KRUEGER et al., 2009).

Diferente do BFV, o índice de pulsatilidade (PI) apresenta um aumento linear durante as quatro primeiras semanas após o parto, o que pode ocorrer devido à vasoconstrição dos vasos carunculares. Embora a involução uterina complete-se por volta de 45 dias pós-parto, foi relatado que o PI continua alterado no dia 86, sem atingir ainda seu valor mínimo (KRUEGER et al., 2009).

Em vacas holandesas, as variações do PI não cessam após a primeira ovulação pós-parto, assim como não há influência da atividade ovariana cíclica sobre os parâmetros de fluxo sanguíneo. O número de crias é um fator a ser considerado, já que foi observado que animais com mais de duas lactações apresentam valores de BFV mais altos. Quanto à fertilidade, animais que ficaram gestantes antes de 86 dias pós-parto não apresentaram diferenças significativas no PI após o dia 14 (KRUEGER et al., 2009).

\subsection{RELAÇÃO COM A ATIVIDADE OVARIANA}

O início da atividade ovariana corresponde ao momento em que os níveis de prostaglandinas atingem, pela primeira vez, os valores basais após o parto (HORTA, 1995).

Com o início da atividade ovariana, inicia-se uma alternância cíclica entre as concentrações de estrógenos, progesterona e prostaglandina na circulação, resultante de interações entre útero, ovário, hipotálamo e hipófise. Neste período, que se inicia normalmente antes da involução completa do útero, as taxas de involução do cérvix e do útero são influenciadas significativamente pelo momento em que se inicia a atividade ovariana (MARQUES; HORTA, 1987).

$O$ retorno à atividade ovariana é marcado pela ocorrência de ciclos estrais curtos. Em gado de leite, ciclos estrais curtos podem ser verificados em $50 \%$ das vacas no início do período pósparto (FERREIRA et al., 2007).

O 1 o ciclo estral, seguido de ovulação, é de aproximadamente 17 dias de duração. Muitos dos primeiros estros pós-parto com ovulação são silenciosos, e o cio clássico somente será observado em 20 a $30 \%$ das vacas européias com corpo lúteo no 30 dia (KOZICKI, 1998).

Há correlação positiva da 1a ovulação (ciclo normal) com a completa involução uterina. Isto significa que animais com mais rápida involução uterina retornarão também mais rapidamente à atividade ovariana (KOZICKI, 1998).

\subsection{FATORES QUE INFLUENCIAM}

As complicações durante o parto e puerpério estão significativamente correlacionadas com a involução uterina (ZAIN et al., 1995). Partos distócicos, gestação gemelar, prolapso uterino, retenção de placenta e infecção uterina podem atrasar o processo de involução (LANDIMALVARENGA, 2006; ZAIN et al., 1995).

O número de partos da vaca é outro fator de grande influência. Sánchez et al. (1999) descrevem tendência de aumento de tempo de involução à medida que aumenta o número de partos. Por outro lado, animais em lactação possuem involução uterina mais rápida (JAINUDEEN; HAFEZ, 1995).

Além disto, a literatura relata diferença na duração do processo de acordo com a raça da fêmea. Segundo Landim-Alvarenga (2006), raças taurinas apresentam involução com duração média de 30 a 60 dias, enquanto animais zebuínos de 100 a 120 dias. A involução uterina pode estar completa a partir de 45 dias após o parto em animais oriundos de cruzamento holandês-

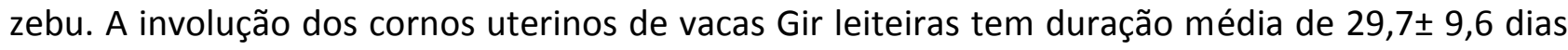


e, na maioria das vezes, a involução da porção cervical demora mais que 43 dias. Em raças européias, $85 \%$ dos animais completam a involução uterina até o 42 이a pós-parto (SÁNCHEZ et al., 1999).

\section{CONSIDERAÇÕES FINAIS}

Para o retorno à atividade reprodutiva de vacas pós-parto, é importante uma involução uterina rápida. A involução é um fator chave durante o período puerperal, já que está diretamente relacionada ao retorno da atividade ovariana cíclica e, consequentemente, uma nova concepção. Sabe-se que a PGF2 $\alpha$ é o hormônio relacionado ao processo de involução. No entanto, mais estudos se fazem necessários acerca da existência de receptores FP no miométrio e endométrio de bovinos pós-parto. Desse modo, será possível desenvolver protocolos hormonais mais eficazes, maximizando os índices de eficiência reprodutiva de rebanhos bovinos.

\section{REFERÊNCIAS}

ANDERSON, L. E.; SCHULTZ, M. K.; WILTBANK, M. C. Prostaglandin moieties that determine receptor binding specificity in the bovine corpus luteum. Journal of Reproduction and Fertility, v. 116, p. 133-141, 1999. https://doi.org/10.1530/irf.0.1160133

ARTHUR, G. H.; NOAKES, D. E.; PEARSON, H. Veterinary reproduction and obstetrics. 6a ed. Bail. Tind., 1989, p. 161-171.

ASSELIN, E.; DROPLET, P.; FORTIER, M. A. Cellular mechanisms involved during oxytocin-induced prostaglandin F2 alfa production in endometrial cells in vitro: role of cycloxygenase 2 . Endocrinology, v. 138, p. 4798-4805, 1997. https://doi.org/10.1210/endo.138.11.5527

ASSELIN, E.; FORTIER, M. A. Detection and regulation of the messenger for a putative bovine endometrial 9-keto-prostaglandin E2 reductase: effect of oxytocin and interferon-tau. Biology of Reproduction, v. 62, p. 125-31, 2000. https://doi.org/10.1095/biolreprod62.1.125

AULETTA, F.; FLINT, A. P. Mechanisms controlling corpus luteum function in sheep, cows, nonhuman primates, and women especially in relation to the time of luteolysis. Endocrinology Review, v. 9, p. 88-105, 1988. https://doi.org/10.1210/edrv-9-1-88

BEKANA, M.; ODENSVIK, K.; KINDAHL, H. Prostaglandin F2alpha metabolite and progesterone profiles in post-partum cows with retained foetal membranes. Acta Veterinaria Scandinavia, v.37, n.2, p.171-185, 1999.

BENCHARIF, D.; TAINTURIER, D.; SLAMA, H.; BRUYAS, J. F.; BATTUT, I.; FIENI, F. Prostaglandins and post-partum period in the cow. Revista de Medicina Veterinaria, v.151, n.5, p.401-408, 2000.

FERNANDES, C. A. C.; FERREIRA, A. M.; VIANA, J. H. M. Efeito do cloprostenol sódico no pós-parto de vacas leiteiras sobre o retorno da atividade reprodutiva. A Hora Veterinária, ano 22, n.126, 2002.

FERNANDES, C. A. C.; FIGUEIREDO, A. C. S. Avanços na utilização de prostaglandinas na reprodução de bovinos. Revista Brasileira de Reprodução Animal, v.31, n.3, p.406-414, 2007. 
FERNANDES, C. A. C.; FIGUEIREDO, A. C. S.; OliVEIRA, E. R.; VASCONCELOS, T. D. Melhoria da eficiência reprodutiva em gado de corte com a aplicação de cloprostenol sódico no pós-parto. A Hora Veterinária, ano 24, n. 142, 2004.

FERNANDES, C. A. C.; OLIVEIRA, E. R.; VASCONCELOS, T. D. Melhoria da performance reprodutiva em vacas de corte com a aplicação de cloprostenol no pós-parto. Revista Brasileira de Reprodução Animal, v. 27, n. 3, 2003.

FERNANDES, C. A. C.; VASCONCELOS, T. D.; VIANA, J. H. M.; FIGUEIREDO, A. C. S.; OLIVEIRA, E. R.; ALVES, B. F. L. Eficiência de duas doses de Cloprostenol (Ciosin ") no pós-parto de vacas de corte. In: Cong. Bras. de Reprod. Anim., 17, 2007. Anais... Curitiba: CBRA, 2007.

FERRAZ, P. C. Efeito do cloprostenol (PGF2 $\alpha$ ) sobre o puerpério de búfalas (Bubalus bubalis) leiteiras da raça Murrah. Itapetininga, 2006. 79p. Dissertação (Mestrado) - Universidade Estadual do Sudoeste da Bahia.

FERREIRA, M. B.; LOPES, B. C.; SOUZA, J. C.; AZEVEDO, N. A.; FERNANDES, L. O.; RIBEIRO, S. A.; ROCHA, A. A. Atividade ovariana pós-parto e ciclo curto em multíparas Bos indicus da raça Gir leiteira. In: Congresso Brasileiro de Reprodução Animal, 17, 2007. Anais... Curitiba: CBRA, 2007. p. 117-120.

FORD, S. P. Control of uterine and ovarian blood flow throughout the estrous cycle and pregnancy of ewes, sows and cows. Journal of Animal Science, v. 55, n. 2, p. 32-42, 1982.

GIER, H. T.; MARION, G. B. Uterus of the cow after parturition: involutional changes. American Journal of Veterinary Research, v. 29, p. 83-96, 1968.

GRIFFIN, B. W.; MAGNINO, P. E.; PANG, I. H.; SHARIF, N. A. Pharmacological characterization of a FP prostaglandin receptor on rat vascular smooth muscle cells (A7r5) coupled to phosphoinositide turnover and intracellular calcium mobilisation. Journal of Pharmacology Expert Theriogenology, $v$. 286, p. 411-418, 1998.

GRUNERT, E.; BIRGEL, E. H. Obstetrícia Veterinária. Ed. Sulina, Porto Alegre, p.106-138, 1982.

GUILBAULT, L. A.; THATCHER, W. W.; FOSTER, D. B.; CATON, D. Relationship of 15-keto-13,14 dihydro-prostaglandin F2 alpha concentrations in peripheral plasma with local uterine production of $\mathrm{F}$ series prostaglandins and changes in uterine blood flow during the early postpartum period of cattle. Biology of Reproduction, v. 31, p. 870-878, 1984. https://doi.org/10.1095/biolreprod31.5.870

HERTELENDY, F.; ZAKAR, T. Regulation of myometrial smooth muscle functions. Current Pharmaceutical Design, n. 10, v. 20, p. 2499-2517, 2004. https://doi.org/10.2174/1381612043383926

HORTA, A. E. M. Fisiologia do puerpério na vaca. In: 8as Jorn. Inter. de Reprod. Anim., 1995. Anais... p. 73-84

JAINUDEEN, M. R.; HAFEZ, S. E. Gestação, fisiologia pré-natal e parto. In: HAFEZ, E.S.E. Reprodução Animal, 6a ed., Ed. Manole, p.217-240, 1995. 
KASIMANICKAM, R.; DUFFIELD, T. F.; FOSTER, R. A.; GARTLEY, C. J.; LESLIE, K. E.; WALTON, J. S.; JOHNSON, W. H. Endometrial citology and ultrasonography for the detection of subclinical endometrites in postpartum dairy cows. Theriogenology, v. 62, p. 9-23, 2004. https://doi.org/10.1016/j.theriogenology.2003.03.001

KINDAHL, H.; LINDELL, J. O.; EDQVIST, L. E. Release of prostaglandin F2 $\alpha$ during the oestrous cycle. Acta Veterinaria Scandinavia, v. 77, p. 143-58, 1981.

KINDAHL, H.; ODENSVIK, K.; AIUMLAMAI, S.; FREDRIKSSON, G. Utero-ovarian relationship during the bovine post partum period. Animal Reproduction Science, v.28, p.363-369, 1992. https://doi.org/10.1016/0378-4320(92)90122-T

KINDHAL, H.; BEKANA, M.; KASK, K. Endocrine aspects of the uterine involution in the cow. Reproduction of Domestic Animals, v. 34, 1999.

KOZICKI, L. E. Aspectos fisiológicos e patológicos do puerpério em bovinos. Archive of Veterinary Science, v.3, n.1, p. 9-19, 1998. https://doi.org/10.5380/avs.v3i1.3733

KRUEGER, L.; KOERTE, J.; TSOUSIS, G.; HERZOG, K.; FLACHOWSKY, G.; BOLLWEIN, H. Transrectal Doppler sonography of uterine blood flow during the first 12 weeks after parturition in healthy dairy cows. Animal Reproduction Science, v. 114, p. 23-31, 2009. https://doi.org/10.1016/i.anireprosci.2008.09.006

LAMMING, G. E.; FOSTER, J. P.; BULMAN, D. C. Pharmacological control of reproduction cycles. Veterinary Records, v.104, p.156-160, 1979. https://doi.org/10.1136/vr.104.8.156

LANDIM-ALVARENGA, F. C. Parto normal. In: Obstetrícia Veterinária. Rio de Janeiro: Guanabara Koogan, 2006. p. 82-96

LOPES, D. T. Efeitos da utilização de prostaglandina F2alfa durante o puerpério precoce sobre a eficiência reprodutiva de vacas leiteiras. 2007. 60p. Dissertação de Mestrado em Ciência Animal Escola de Veterinária, Universidade Federal de Goiás, Goiânia.

MACHADO, P. F.; REZENDE, J.; CASSOLI, L. D.; SORIANO, S. Efeito do cloprostenol sódico (Ciosin ${ }^{\circledR}$ ) sobre parâmetros reprodutivos e produtivos no pós-parto de vacas leiteiras com ou sem retenção de placenta. A Hora Veterinária, v. 23, n. 135, 2003.

MARQUES JÚNIOR, A. P. Fisiologia do Puerpério na Vaca. In: Congresso Brasileiro de Reprodução Animal, 1993. Anais... Belo Horizonte: CBRA. 1993. p. 58-69.

MARQUES, C. C., HORTA, A. E. M. Completion of uterine involution and onset of postpartum ovarian activity and their correlation with retained placenta and metritis in dairy cows. In: An. Meet. of the EAAP, 38, 1987. Anais... Lisboa, 1987. v. 1, p. 584.

MATSUMOTO, T.; SAGAWA, N.; YOSHIDA, M.; MORI, T.; TANAKA, I.; MUKOYAMA, M.; KOTANI, M.; NAKAO, K. The PGE2 and F2 $\alpha$ receptor genes are expressed in human myometrium and are downregulated during pregnancy. Biochem. Biophysical Research Community, v. 238, p. 838-841, 1997. https://doi.org/10.1006/bbrc.1997.7397 
MELENDEZ, P.; MCHALE, J.; BARTOLOME, J.; ARCHBALD, L. F.; DONOVAN, G. A. Uterine involution and fertility of holstein cows subsequent to early postpartum PGF2alfa treatment for acute puerperal metrits. Journal Dairy Science, v. 87, p. 3238-3246, 2004. https://doi.org/10.3168/ids.S0022-0302(04)73460-8

MILNE, S. A.; JABBOUR, H. N. Prostaglandin (PG) F2 $\alpha$ receptor expression and signaling in human endometrium: role of PGF $2 \alpha$ in epithelial cell proliferation. Journal of Clinical and Endocrinology Metabolism, v. 88, n. 4, p. 1825-1832, 2003. https://doi.org/10.1210/ic.2002-021368

NOAKES, D. E. Fertilidade e obstetrícia em bovinos. 1ạ ed. São Paulo: Varela, 1991. 139p.

OKUDA, K.; MIYAMOTO, Y.; SKARZYNSKI, D. J. Regulation of endometrial prostaglandin F2 $\alpha$ synthesis during luteolysis and early pregnancy in cattle. Domestic Animal Endocrinology, v. 23, p. 255-264, 2002. https://doi.org/10.1016/S0739-7240(02)00161-3

SALAMONSEN, L. A.; FINDLAY, J. K. Regulation of endometrial prostaglandins during the menstrual cycle and in early pregnancy. Reproduction Fertility and Development, v. 2, p. 443-57, 1990. https://doi.org/10.1071/RD9900443

SÁNCHEZ, J. P. G.; SOBRINHO, E. B.; GONÇALVES, A. A. M. Involução uterina em um rebanho Gir leiteiro segundo o período pós-parto e o número de parições. Arquivo Brasileiro de Medicina Veterinária e Zootecnia, v.51, n.4, 1999.

SENGER, P. L. Pathways to pregnancy and parturition. Pullman: Current conceptions, second edition. 2003.

SENIOR, J.; SANGHA, R.; BAXTER, G. S.; MARSHALL, K.; CLAYTON, J. K. In vitro characterization of prostanoid FP-, DP-, IP- and TP-receptors on the non-pregnant human myometrium. Brazilian Journal of Pharmacology, v. 107, p. 215-221, 1992. https://doi.org/10.1111/j.14765381.1992.tb14489.x

SHELDON, I. M.; LEWIS, G. S.; LEBLANC, S.; GILBERT, R. O. Defining postpartum uterine disease in $\begin{array}{llllll}\text { cattle. Theriogenology, } & \text { v. } & \text { b5, } & 1516-1530, & \end{array}$ https://doi.org/10.1016/j.theriogenology.2005.08.021

SHIRAR, A.; MARTINET, J. Postpartum ovarian activity and its interaction with the uterus in resuming cyclic activity post partum. Current Topics of Veterinary Medicine and Animal Science, v. 20, p. 67-94, 1982.

SISSON, S. Aparelho Urogenital. In: GETTY, R. Anatomia dos Animais Domésticos. 5 ed. Rio de Janeiro: Guanabara Koogan, 1986. p. 879-895.

SKARZYNSKI, D. J.; BOGACKI, M.; KOTWICA, J. Involvement of ovarian steroids in basal and oxytocin-stimulated PGF2 $\alpha$ secretion by the bovine endometrium. Theriogenology, v. 52, p. 38597, 1999. https://doi.org/10.1016/S0093-691X(99)00137-5

SKARZYNSKI, D. J.; MIYAMOTO, Y.; OKUDA, K. Production of prostaglandin F2 $\alpha$ by cultured bovine endometrial cells in response to tumor necrosis factor $\alpha$ : cell type specificity and intracellular 
mechanisms. Biology of Reproduction, v. 62, p. 1116-20, 2000. https://doi.org/10.1095/biolreprod62.5.1116

SUGIMOTO, Y.; YAMASAKI, A.; SEGI, E.; TSUBOI, K.; AZE, Y.; NISHIMURA, T.; OIDA, H.; YOSHIDA, N.; TANAKA, T.; KATSUYAMA, M.; HASUMOTO, K.; MURATA, T.; HIRATA, M.; USHIKUBI, F.; NEGISHI, M.; ICHIKAWA, A.; NARUMIYA, S. Failure of parturition in mice lacking the prostaglandin $F$ receptor. Science, v. 277, p. 681-684, 1997. https://doi.org/10.1126/science.277.5326.681

TORIBIO, J. Blood levels of the prostaglandin F2alpha metabolite during the postpartum period in Bos indicus cows in the humid tropics. Journal of Veterinary Medicine, v. 41, n. 8, p. 630-639, 1994. https://doi.org/10.1111/i.1439-0442.1994.tb00130.x

XIAO, C. W.; LIU, J. M.; SIROIS, J.; GOFF, A. K. Regulation of cyclooxygenase-2 and prostaglandin F synthase gene expression by steroid hormones and interferon-t in bovine endometrial cells. Endocrinology, v. 139, p. 2293-9, 1998. https://doi.org/10.1210/endo.139.5.5961

ZAIN, A. E.; NAKAO, T.; ABDEL, M. Factors in the resumption of ovarian activity and uterine involution in postpatum dairy cows. Animal Reproduction Science, v.38, n.3, p. 203-214, 1995. https://doi.org/10.1016/0378-4320(94)01359-T

ZANCHET, E. Efeito de duas injeções de prostaglandina F2 $\alpha$ após o parto na performance reprodutiva de vacas leiteiras e eficiência reprodutiva entre raças Holandesa e Jersey. A Hora Veterinária, v. 24, n. 143, 2005. 